\title{
Reichenbach: scientific realist and logical empricist?
}

\author{
Matthias Neuber ${ }^{1}$
}

Received: 20 November 2020 / Accepted: 28 April 2021 / Published online: 12 May 2021

(c) The Author(s) 2021

\begin{abstract}
Hans Reichenbach's position in the debate over scientific realism is remarkable. On the one hand, he endorsed the programmatic premises of logical empiricism; on the other, he explicitly employed a realist approach to conceptions such as reference, causality, and inference to the best explanation. How could that work out? It will be shown in the present paper that in Reichenbach's view scientific realism is not, as frequently assumed, opposed to logical empiricism but rather to logical positivism. A distinction without a difference? Not at all, at least for Reichenbach. As is well known, his particular-probabilistic_-variant of logical empiricism was intended to circumvent what he considered the shortcomings of the Vienna Circle's verificationist (reductionist) approach to the language of science. In Experience and Prediction (1938), Reichenbach became most explicit in this regard. However, I shall argue that his position remained notoriously unstable in the end. It oscillated between a fullfledged scientific realist reading and an eminently pragmatist reading. Nevertheless, Reichenbach's contribution proved instrumental in preparing subsequent efforts at reconciling logical empiricism and scientific realism.
\end{abstract}

Keywords Reichenbach · Logical empiricism · Scientific realism · Probability · Inference to the best explanation · Pragmatism

\section{Introduction}

Hans Reichenbach's attempt at demarcating Berlin-style 'logical empiricism' from Viennese 'logical positivism' is well known (for a skeptical assessment, see Uebel, 2013, pp. 73-77 and 85-88). Presupposing the adequacy of the distinction as such, Herbert Feigl retrospectively reported:

This article belongs to the topical collection on All Things Reichenbach, edited by Erik Curiel and Flavia Padovani.

Matthias Neuber

maneuber@uni-mainz.de

1 Department of Philosophy, Johannes Gutenberg University Mainz, Mainz, Germany 
Perhaps the most important and constructive aspect in the transition to Logical Empiricism was the element of empirical or scientific realism that became increasingly prominent in our views. Reichenbach and I had already opposed the phenomenalistic reduction during the twenties. In this regard we were closer to the views of Zilsel and Popper. We regretted that Schlick had abandoned his early critical realism, and we tried to reinstate it in a more defensible form. (1981, p. 80)

As regards Reichenbach in particular, it is no secret that the form of realistically inspired logical empiricism he defended stood in sharp contrast to Rudolf Carnap's early project of a 'logical construction of the world' (see Carnap, 1928a). It was the phenomenalistic reading of this project Reichenbach considered the most outstanding contemporary variant of 'logical positivism' (and, thus, scientific anti-realism). In his Experience and Prediction from 1938, Reichenbach became most explicit in this regard. However, as I would like to argue in this paper, his position remained notoriously unstable in the end. It oscillated between a full-fledged scientific realist reading and an eminently pragmatist reading.

In what follows, I will proceed in four main steps. First, I shall briefly reflect on Reichenbach's transition from Kantianism to logical empiricism (Sect. 2). Second, I shall discuss the close connection between the promotion of empiricism and the rejection of positivism as it documents itself in Reichenbach's seminal Experience and Prediction (Sect. 3). Third, the cubical-world analogy-a thought experiment provided by Reichenbach in order to flesh out the realist implications of his particular approach—will be scrutinized (Sect. 4). Fourth, some of the principal exegetical problems associated with this approach are going to be investigated at some length (Sect. 5). Finally, by way of conclusion, I shall summarize my findings and give a short glimpse on Reichenbach's impact (Sect. 6).

\section{From Kantianism to logical empiricism}

In the early years of his philosophical career, Reichenbach defended a particular Kantian point of view. Thus in his 1915 doctoral thesis Der Begriff der Wahrscheinlichkeit für die mathematische Darstellung der Wirklichkeit and especially in his 1920 Relativitätstheorie und Erkenntnis Apriori, he made (more or less) extensive use of transcendental arguments (see Eberhardt, 2011 and Friedman, 1999, ch. 3; further Neuber, 2018a, pp. 74-77). His conception of a 'relativized apriori' figures prominently in this regard (see again Friedman, 1999, ch. 3). Yet, as early as 1921 Reichenbach left the (neo-)Kantian community and converted to an explicitly conventionalist account of science and scientific theory construction (see Reichenbach, 1921). As is well known, it was Moritz Schlick who sustainably influenced Reichenbach in this direction (see Friedman, 1999, pp. 60-64; further Coffa, 1991, p. 203).

However, in his further philosophical development, Reichenbach turned out as an uneasy ally of Schlick, Carnap, and the other members of the Vienna Circle. Thus in his 1933 review of Carnap's Der logische Aufbau der Welt, he complained that the latter's "logistic neo-positivism" (Reichenbach, 1933, p. 200) prevented 
any consideration of probability in scientific inference and knowledge acquisition. ${ }^{1}$ Reichenbach, who had helped establish the Berlin Gesellschaft für wissenschaftliche Philosophie in the late 1920s (see Milkov \& Peckhaus, 2013), sharpened this critique in his survey article "Logistic Empiricism in Germany and the Present State of its Problems," which appeared in 1936 in The Journal of Philosophy. There, he made it clear that

[t]he tautological character of the positivistic system [...] could not justify the predictive character of science. The system, in its seductive symmetry, lacked one essential quality: it did not correspond to the meanings of propositions, as these are expressed in the practice of science. It could not develop a theory of propositions about the future. (1936, p. 152)

Interestingly enough, it was in this very context that Reichenbach drew a principled distinction between positivism, on the one hand, and empiricism, on the other. In his own words:

This was the precise reason why the Berlin group could not accept positivism. The members of this circle insisted upon the necessity of a theory of propositions about the future. They maintained that any philosophy which neglected the fact and function of propositions about the future in science flagrantly contradicted the very first condition of empiricism: viz., to correspond to the practice of science. (ibid.)

As Reichenbach further pointed out, "propositions about the future cannot be expected to state certain truths" (p. 153). What is needed, therefore, is a "probability-logic" (p. 154) that deviates from the standard (Frege-Russellian) "two-valued schema" (ibid.). Again, in Reichenbach's own words: "It is the task of modern logic to construct the wider frame of probability-logic, for [...] it is within this frame that a theory of knowledge can be obtained which corresponds to the actual state of science." (pp. 154-5) Beyond the shadow of a doubt, it was the development of quantum mechanics that lurked in the background here (see already Reichenbach, 1930 in this connection). But be that as it may, the probability concept was considered by Reichenbach as the key concept of a logical empiricist account of science in general. $^{2}$

\footnotetext{
1 Reichenbach obviously borrowed the term 'logistic neo-positivism' from Eino Kaila who had introduced it in his 1930 critical monograph Der logistische Neupositivismus.

2 A couple of annotations - for the most part suggested by comments from the two anonymous reviewers of the present paper - should be added in this context. First, it must be seen that Reichenbach's juxtaposition of 'logical empiricism' and 'logical positivism' can hardly be confirmed by relevant primary sources. As one of the two reviewers puts it: "The members of the Vienna Circle too in fact distanced themselves from the label 'logical positivism'. With the exception of Feigl and Blumberg's 'Logical Positivism: A New Movement in European Philosophy' (1931), the label was primarily used as a pejorative attribution from outside. The leading members of the Vienna Circle themselves, on the other hand, preferred labels such as 'scientific empiricism' (Neurath), 'consistent empiricism' (Schlick), or 'scientific philosophy' (Carnap)." Nevertheless, in terms of content there indeed were the differences diagnosed by Reichenbach, at least so in the late 1920 s and the early 1930s. Second, it might be plausibly suspected that Reichenbach's "Logistic Empiricism in Germany" was prompted by Ernest Nagel's report about analytic philosophy in Europe where Nagel devoted only one short footnote to Reichenbach (see Nagel 1936,
} 


\section{Experience and prediction}

During the second half of the 1930s, logical positivism in its originally Viennese variant went through a process of liberalization. This process of liberalization pertained primarily to the verificationist criterion of meaning, as it was mainly defended by Friedrich Waismann, Schlick, and the early Carnap. As a consequence of the Vienna Circle's protocol-sentence debate, direct verification as a criterion of meaning became more and more unattractive. First and foremost, Carnap attempted to supplant it by the weaker criteria of confirmability (see Carnap, 1936) and testability (see Carnap, 1936/7; further the retrospectives in Hempel, 1950 and Feigl, 1951). Moreover, Carnap made a move toward semantics in the vein of Alfred Tarski (see Uebel, 2007, pp. 333-342).

Given this context, it is interesting to see that Reichenbach noticed a significant rapprochement particularly with Carnap. Thus in his 1938 Experience and Prediction, Reichenbach declares:

The more tolerant representatives of positivism recognized [the] discrepancy between their theory and actual science; and so they looked for an expansion of the narrow definition of meaning previously accepted. Carnap in some recent publications has developed an expansion of the criterion of the meaningful in which the idea of absolute verification is abandoned; he introduces instead the concept of "degree of confirmation," which furnishes a graduated series of propositions, and which is to apply to predictions as well as to propositions concerning past events. This "degree of confirmation" corresponds, in many respects, to our "weight"; with the difference, however, that Carnap doubts whether it is identical with "probability." It seems to me a sign of great progress that with this new theory of Carnap the development of the conceptions of the Vienna Circle turns in a direction closer to the actual state of knowledge; with this change an old difference between Carnap's conceptions and mine, which was the subject of many a discussion, is considerably reduced. (Reichenbach, 1938, p. 76)

It should be added that by 'weight' Reichenbach means nothing but the degree of probability. In cases where we cannot determine the truth or falsehood of a proposition, the determination of weight serves as "a substitute for verification, but an indispensable one, since we cannot renounce forming an opinion about unverified sentences" (1938, p. 24). Accordingly it is again the concept of probability that figures

\section{Footnote 2 (continued)}

p. 30, fn. 2). In a sense, Reichenbach (at that time already in Istanbul) could have been forced to emphasize the differences when he saw that nearly everyone ignored him and his allies in Berlin. At any rate, it appears dubious whether the way Reichenbach drew the distinction between positivism and empiricism in 1936 still corresponded to the actual state of the art. Many people from Berlin, and even from Vienna, were already lost, moved, dead. Many earlier positions were abandoned (see the next section for details). Thus one might raise the question whether Reichenbach's distinction was just a strong 'marketing issue' in 1936. However, to further speculate about this matter would clearly exceed the framework of this paper. 
prominently in Reichenbach's account. With the help of this concept he attempts to tackle problems such as meaning, theory testing, and-not at least-the realism issue. Thus, in the preface to Experience and Prediction, Reichenbach states:

If the present book enters once more into the discussion of these fundamental problems, it is because former investigations did not sufficiently take into account one concept which penetrates into all the logical relations constructed in these domains: that is, the concept of probability. It is the intention of this book to show the fundamental place which is occupied in the system of knowledge by this concept and to point out the consequences involved in a consideration of the probability character of knowledge. (1938, p. vi)

Consequently, Reichenbach does not hesitate to characterize his particular version of the logical empiricist program as a "combination of my investigations on probability with the ideas of an empiricist and logistic conception of knowledge" (p. vii). In short, Reichenbach's is a "probabilistic empiricism" (p. viii).

With these considerations on the table, we are in a position to give a concise summary of the thematically central issues dealt with in Experience and Prediction. Thus, to begin with, Reichenbach starts his investigation with an analysis of the concept of meaning (chapter I), followed by a discussion of the relation of sense impressions to the 'outer' world of concrete objects (chapters II and III). Then, he extensively reflects on the status of theoretical ('unobservable') entities (chapter IV) and finally provides a detailed examination of the problem complex of probability and induction (chapter V). For our present context, chapters II and IV are to be considered most relevant.

However, the analysis of the concept of meaning (as offered in chapter I) should not be omitted. For it is here that Reichenbach lays the foundation for his probabilistic variant of logical empiricism. So what is, according to Reichenbach, to be understood by 'meaning?' Most generally speaking, meaning for Reichenbach is "a function symbols acquire by being put into a certain correspondence with facts" (1938, p. 9; emphasis in the original). However, there must be distinguished between (a) the "truth theory of meaning" (p. 33; emphasis omitted) and (b) the "probability theory of meaning" (p. 46). Whereas the truth theory of meaning goes hand in hand with logical positivism, the probability theory of meaning is correlated with logical empiricism. So, what exactly makes the difference between these two conceptions? ${ }^{3}$

First of all, it should be noted that according to the truth theory of meaning a proposition has meaning if and only if it is observationally verifiable (or falsifiable). Thus meaningful propositions are in principle bound to observation. Yet what, then, about statements dealing with entities and processes that are not observable by the unaided senses, such as atoms or electromagnetic fields? Here, the truth theory of

\footnotetext{
${ }^{3}$ Elliott Sober rightly asks in this connection: "Who are these dogmatic and prickly positivists whom Reichenbach found so irritating? Presumably not the gentle Carnap; maybe the testy Neurath or the recently murdered Schlick?" (Sober 2011, p. 19, fn. 18). Again, it must be recognized that 'logical positivism' at that time (1938) was hardly tied to any real figures in the concrete philosophical arena. Rather, it served Reichenbach as (a more or less abstract) contrast foil to sharpen his own, logical empiricist, conception.
} 
meaning implies that an indirect verification must be possible. This, in turn, amounts to the view that propositions which cannot be directly verified must be reducible to other propositions capable of direct verification. Both types of propositionsReichenbach calls them "direct" and "indirect" propositions, respectively (see p. 47) - stand in an equivalence relation to each other. Thus, according to the truth theory of meaning, an indirect proposition $A$ must be transferrable into an aggregate of propositions $\left[a_{1}, a_{2}, \ldots, a_{n}\right]$, so that the following equivalence can be stated:

$$
A \equiv\left[a_{1}, a_{2}, \ldots, a_{n}\right]
$$

The equivalence symbol ' $\equiv$ ' signifies the equality of truth values, that is: according to the truth theory of meaning, an indirect proposition can be-salva veritatetransferred into a concatenation of direct propositions. Consequently, the meaning of both types of propositions is the same in cases such as this.

Reichenbach thinks this view is misguided, the reason being that in scientific practice infinitely many direct propositions can be inferred from a given indirect proposition. He points out: "It is true that the class of propositions from which we start in order to infer $A$ is a finite one, and even a practically finite one; for what we have is always a finite number of propositions. But the class of propositions which we can infer from $A$ is not finite." (p. 50) Accordingly, the positivistic equivalence demand can never be satisfied because the right-hand part of the equivalence relation (1) "can never be practically given" (ibid.). This means, in other words, that indirect propositions such as $A$ possess a non-reducible surplus meaning. And it is exactly this sort of surplus meaning that enables scientists to make predictions. In Reichenbach's own words:

It is because a physical statement $A$ includes predictions for future observations that it contains a surplus meaning compared with the set $\left[a_{1}, a_{2}, \ldots, a_{n}\right]$; and it is the indeterminateness of the future which battles the equivalence theory of positivism concerning indirect sentences. (p. 51)

Thus Reichenbach's critique of (logical) positivism can be nailed down to the insight that the truth theory of meaning underlying it cannot account for the prognostic function of scientific theory construction. ${ }^{4}$

By accounting more subtly for the needs of actually practiced science, Reichenbach maintains, the alternative probability theory of meaning results, as it were, by itself. According to this theory, a proposition has meaning if and only if it is possible to determine its weight, that is, its degree of probability. In Reichenbach's view, the "man of science" (p. 55) is, in point of fact, not interested in direct (or 'absolute') verification, but rather in predicting observable events with the highest possible weight. Therefore the need for a probability theory of meaning. The principal feature of this theory is that it interprets the relation between direct and indirect

\footnotetext{
${ }^{4}$ One of the reviewers of the present paper insinuates that it might be objected here that an instrumentalist could entirely agree with focusing on predictions as the principal aim of science, albeit without being committed to any form of realistic semantics. As will be seen in the next section, though, Reichenbach provides some sort of no-miracles argument in order to block the instrumentalist turn.
} 
propositions as a "probability implication" (p. 51). ${ }^{5}$ In a first instance, this probability implication might be formalized as follows:

$$
\left[a_{1}, a_{2}, \ldots, a_{n}\right]=>_{p} A
$$

The operator ' $=>_{\mathrm{p}}$ ' denotes the probability implication as such and says that the indirect proposition $A$ can be derived with a certain (inductive) probability from the aggregate of direct propositions $\left[a_{1}, a_{2}, \ldots a_{n}\right]$. However, the implication can also be stated the other way round (i.e., abductively), so that we get:

$$
A=>_{p}\left[a_{1}, a_{2}, \ldots, a_{n}\right]
$$

Since the junction of two implications gives an equivalence we obtain a probabilistic analogon to the equivalence relation demanded by the truth theory of meaning. Reichenbach speaks of the "probability connection" (p. 52) in this context and provides the following formalization:

$$
A<=>_{p}\left[a_{1}, a_{2}, \ldots, a_{n}\right]
$$

According to (4), two propositions have the same meaning if they "obtain the same weight, or degree of probability, by every possible observation" (p. 54).

It should be re-emphasized that Reichenbach thinks of the probability theory of meaning as being justified by the concrete practice of science. In his view, "our analysis leads to ascribe a unique position to the probability theory of meaning. It is just this theory of meaning which is distinguished by the postulate of a relation between meaning and action." (p. 70) Since, according to Reichenbach, "actions are to be based on statements concerning the future" (ibid.) and since statements such as these are to be couched in probabilistic terms the probability theory of meaning definitely accounts for the prognostic task of science. The truth theory of meaning, on the other hand, is "too narrow" (ibid.) in this regard. Reichenbach therefore concludes:

The key to a theory of meaning corresponding to the intentions of physics lies in the probability problem. It has been the fate of the positivistic doctrines that they have been driven by logical criticism into an intellectual asceticism which has suppressed all understanding of the "bridging" task of science-the task of constructing a bridge from the known to the unknown, from the past to the future. The cause for this unhealthy doctrinairism is to be found in underestimating the concept of probability. Probability is not an invention made for the sort of gamblers, or for the business of social statistics; it is the essential form of every judgment concerning the future and the representative of truth for any case where absolute truth cannot be obtained. (p. 75)

\footnotetext{
5 As for the rules and details of this theory, Reichenbach is referring the reader to his Wahrscheinlichkeitslehre from 1935. See Galavotti 2011 for further details in this connection.
} 
In short, the quest for certainty and absolute truths is practically illusory and therefore out of place. What we are left with is propositions with higher or lower probability and, whenever indirect propositions are involved, probability connections on the basis of which scientific knowledge is attained and validated. Or, to put it in Reichenbach's more elaborate parlance:

There is no certainty at all remaining - all that we know can be maintained with probability only. There is no Archimedean point of absolute certainty left to which to attach our knowledge of the world; all we have is an elastic net of probability connections floating in open space. (p. 192)

\section{Reduction, projection and the cubical-world analogy}

What does all of this entail for Reichenbach's standing in the debate over scientific realism? In order to adequately answer this question, it is mandatory to consult the so-called cubical-world analogy as it can be found in chapter II, $\S 14$, of Experience and Prediction. However, let us first shed some light on the broader exegetical context: volume 181 of the present journal, which appeared in 2011, contains a special issue devoted to Reichenbach's Experience and Prediction. In the introduction to this issue, Gürol Irzik and Elliott Sober provide the following assessment:

Reichenbach is now often lumped together with the logical positivists of the Vienna Circle, but his ideas, especially those in Experience and Prediction, were often developed in opposition to positivism. Reichenbach frequently sought to save concepts and problems from the many positivists who sought to discredit them. For example, he thought that causality has a place in science and the problem of the external world is not a pseudo-problem. Indeed, Reichenbach always defended realism against positivism, and his defense was truly ingenious. It has been standard for decades to refer complacently to 'the demise of logical positivism,' but the so-called positivists were more various than the standard stereotype would suggest. (Irzik \& Sober, 2011, p. 2)

I entirely agree: In point of fact, Reichenbach's plea for logical empiricism includes a fairly robust argument for scientific realism. Exactly here, I claim, the cubicalworld analogy comes into play. Let us see how and with which consequences.

To begin with, in terms of methodology, Reichenbach already draws in $\S 1$ of Experience and Prediction a distinction between what he calls "volitional decisions," on the one hand, and "volitional bifurcations," on the other (see Reichenbach, 1938, pp. 9-10). This distinction is quite far-reaching because it implies a significant restriction of the conventionalist ingredient in Reichenbach's account of science. To be more precise, volitional decisions pertain primarily to the realm of conventions and, as such, they "represent a choice between equivalent conceptions" (p. 9). For example, both miles and kilometers serve to measure distances and are equivalent regarding the effected cognitive content. Thus it is cognitively insignificant whether the distance between Istanbul and Los Angeles is measured in miles or in kilometers. The time that is needed to travel from the one place to the other is the 
same in both cases. However, there is another type of decisions-namely volitional bifurcations-where it definitely makes a difference which of two (or more) options is chosen. Reichenbach mentions here the axiological contrast between causal explanation and mere description in science. In cases such as this one, Reichenbach maintains, it is not irrelevant which of the existing options is in fact chosen because one does not arrive at equivalent but at divergent results, depending on the very option chosen. Reichenbach writes: "Whereas a convention may be compared to a choice between different ways leading to the same place, the volitional bifurcation resembles a bifurcation of ways which will never meet again." (ibid.)

As Reichenbach further outlines, both volitional decisions and volitional bifurcations might be followed by subsequent decisions, which he calls 'entailed decisions.' Although both volitional decisions and volitional bifurcations as such are freely chosen, entailed decisions are, as it were, binding. Or, as Reichenbach himself puts it:

The system of knowledge is interconnected in such a way that some decisions are bound together; one decision, then, involves another, and, though we are free in choosing the first one, we are no longer free with respect to those following. We shall call the group of decisions involved by one decision its entailed decisions. (p. 13)

Thus, for example, if we decide to measure distances in miles, then an essential entailed decision consists in the renunciation (and inability) of addition of numbers belonging to the decimal system. The crux of the matter here is that, in Reichenbach's view, any extreme form of conventionalism is prevented by employing the concept of entailed decisions. Accordingly, he claims:

The concept of entailed decisions [...] may be regarded as a dam erected against extreme conventionalism; it allows us to separate the arbitrary part of the system of knowledge from its substantial content, to distinguish the subjective and the objective part of science. The relations between decisions do not depend on our choice but are prescribed by the rules of logic, or by the laws of nature. (p. 15) 6

\footnotetext{
${ }^{6}$ In the context of his early "Bericht über eine Axiomatik der Einsteinschen Raum-Zeit-Lehre" from 1921, Reichenbach was less cautious regarding the conventionalist doctrine. In a letter to Moritz Schlick - dated January 18, 1922 - he praised his axiomatic analysis of Albert Einstein's spacetime theory without any reservations as a "confirmation of conventionalism" (see Neuber 2018a, p. 79). In Experience and Prediction, in contrast, Reichenbach is much more critical. "This tendency," he writes, "and above all, in its founder Poincaré, had historical merits, as it led philosophy to stress the volitional elements of the system of knowledge which had been previously neglected. In its further development, however, the tendency has largely trespassed beyond its proper boundaries by highly exaggerating the part occupied by decisions in knowledge. The relation between different decisions were overlooked, and the task of reducing arbitrariness to a minimum by showing the logical interconnections between the arbitrary decisions were forgotten." (1938, pp. 14-5) It is plausible to suspect that Reichenbach is thinking of Hugo Dingler's 'radical' version of conventionalism here. Yet, as one of the reviewers of the present paper suggests, Reichenbach could also have in mind the early Carnap (see, in this connection, Hans Reichenbach to Moritz Schlick, June 13, 1923; Schlick-Nachlass, Inventory no. 115/Reich-11).
} 
With this restriction of the role of conventional elements in science, Reichenbach is in a position to let realism take over.

$\S 13$ of Experience and Prediction should serve as our starting point here. After a brief summary of the "positivistic construction of the world" in $\S 12$, Reichenbach in $\S 13$ systematically discusses the relationship between sense impressions and external things. As he makes it clear from the very beginning, the distinction between "reduction" and "projection" plays a crucial role in this connection (see p. 105). In order to explicate this distinction, Reichenbach makes use of two illustrative examples. Let us call them the brick-wall example and the shadow-bird example, respectively.

Begin with the brick-wall example. A wall built of bricks can be conceived of as a "complex" (ibid.) whose existence depends on a certain configuration of the bricks. If some or all of the bricks are removed, the wall will cease to exist at some moment. Of course, the converse does not hold: the wall can be destroyed but the particular bricks might continue to exist. Propositions concerning the complex (the wall) and propositions concerning its internal elements (the bricks) stand in an equivalence relation to each other which, in turn, allows translating propositions concerning the complex into propositions concerning its elements. In Reichenbach's own words: "To say that the wall has a height of three meters reads in translation that there are bricks stuck together by mortar and piled upon one another to the height of three meters." (ibid.) However, the wall as such is more than the mere sum of the bricks constituting it. The latter could lie scattered on the floor and no wall would be there. Accordingly, the form of the configuration is decisive. Since Reichenbach is presenting the brick-wall example at the level of ontology, he speaks of the "reducibility of existence" in the context given and explains: "the existence of the complex is dependent on the existence of the elements in such a way that the nonexistence of the elements implies the nonexistence of the complex." (ibid.)

The shadow-bird example, on the other hand, has the following structure. Imagine a number of birds flying within a certain domain of space. Imagine further the shadows cast by the birds both in horizontal orientation (on the surface of the earth) and in vertical orientation (for example, on the façade of a house). Reichenbach calls the relation constituted by this twofold shadow system a projection and comments: "every proposition concerning the movement of the birds is coordinated with a proposition about the changes of the pairs of shadows." (p. 108) In this respect, the shadow-bird example and the brick-wall example are analogous to each other. 
However, in contrast to the brick-wall example, we do not have a strict propositional equivalence relation here. Rather, we can only infer with probability from the shadows to the birds (as their possible causes). "This lack of certainty," Reichenbach writes, "is due to the fact that natural processes can never be foreseen with certainty" (p. 109). Moreover, we do not have any reducibility of existence in the shadow-bird example: the birds (the analoga to the wall) continue to exist even if the shadows (the analoga to the bricks) are not present anymore (for example at night). In other words, the birds exist independently of the shadows. The wall, in contrast, can only exist in dependence on the bricks.

It should be sufficiently clear by now what Reichenbach intends to illustrate by the two examples above. In his view, there are two different possibilities to determine the relation between sense impressions and external things, namely either in analogy to the brick-wall example or in analogy to the shadow-bird example. For Reichenbach, only the second scenario is consistent with our epistemic situation. "There is," he concludes.

no equivalence between propositions concerning external things and propositions concerning impressions; there is only a probability connection. This connection is thus a projection and not a reduction; the existence of the external things is not reducible to the existence of impressions; the external things have an independent existence. It is the same kind of independence as between the birds and their shadows. (p. 111)

On the whole, we end up with a global realism concerning the external world of concrete 'projective complexes.'

Now, in $\S 14$ of Experience and Prediction, Reichenbach goes one (essential) step further and expands the shadow-bird illustration to the realm of theoretical entities. We are thus now encountering — eventually — the thought experiment I have previously called 'the cubical-world analogy'. ${ }^{7}$ Reichenbach himself provides the following figure for it (see 1938, p. 117):

\footnotetext{
7 There is a rather recent discussion on the status of thought experiments in empiricism (see Brown 2004 and Norton 2004), into which I cannot enter here. Suffice it to note that Reichenbach's is an epistemologically rather harmless attempt to illustrate his central argument for the independent existence of theoretical entities.
} 


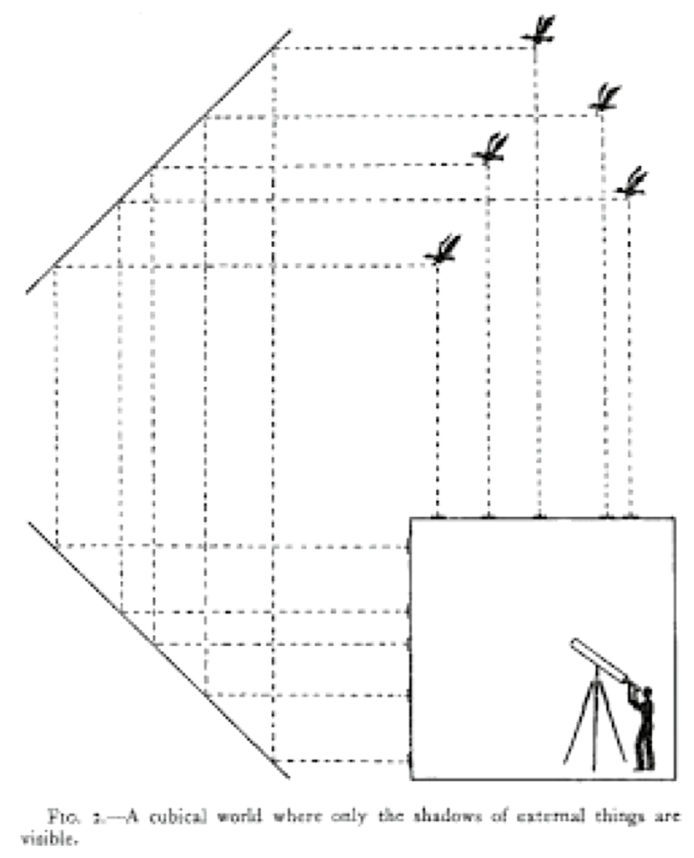

The corresponding story reminds one of Plato's allegory of the cave and goes as follows: Imagine we are all living in a huge cube surrounding or, better, imprisoning us. The walls of the cube are made of sheets of white cloth and translucent as the screen of a cinema, "but not permeable by direct light waves" (p. 116). Outside the cube are flying birds the shadows of which are projected at the same time horizontally on the ceiling of the cube and (with the help of a mirror system) vertically on one of its walls. The people living inside the cube can only perceive the shadows, but not the birds themselves. Consequently, the question arises: "Will these men discover that there are things outside their cube different from the shadow figures?" (ibid.)

Reichenbach's discussion of this question embraces two steps. In the first instance, he suggests, the inhabitants of the cube won't recognize a difference; that is, they will develop a worldview according to which the space surrounding the cube is empty and where at the cube's ceiling and one of its walls there are moving dark dots. However, the story continues, there will come the day when a resourceful physicist (Reichenbach calls him 'Copernicus') discovers with the help of a telescope that the dark dots have the shape of animals (Copernicus will call them 'birds') and that there are corresponding similar pairs of such dots scattered on the ceiling and on one of the walls of the cube, respectively. Since, Reichenbach tells us, the physicist possesses causal intuitions he will infer from the correlation of dots to the existence of the birds and their movements by which the correlated dots are evoked. "He will maintain", Reichenbach writes, "that the strange correspondence 
between the two shades of one pair cannot be a matter of chance but that these two shades are nothing but effects caused by one individual thing situated outside the cube within free space." (p. 118) In other words: the physicist will draw an inference to the best explanation (see, in this connection, the interpretation delivered by Psillos, 2011a, p. 30; see further Salmon, 1994 and esp. Sober, 2011).

To be sure, it is highly plausible to assume that the majority of the cube inhabitants would trust the physicist's explanation. However, there are also the philosophers! As Reichenbach suggests, it would be the positivists, in particular, who would contradict Copernicus. For, according to their truth theory of meaning, propositions concerning the dark dots would be equivalent to propositions concerning the birds (viz. the respective 'reductive complexes'). Just as with the early Carnap's Aufbau, we would be confronted with the view that indirect propositions dealing with theoretically postulated entities (the moving birds outside the cube) are in fact reducible to direct propositions dealing with observable phenomena exclusively (the dark dots on the ceiling and the wall). Thus, when confronted with Copernicus, the positivist would argue as follows:

What you maintain [...] is not false but biased. You say that there are things independent in their existence of the black dots; but you could say, on the same grounds, that these things are identical with the black dots. There is a correspondence between each of your "birds" and a pair of black dots; all that is said about your birds is inferred from the black dots and therefore equivalent to statements about the dots. You believe in a surplus meaning of your hypothesis of the birds, compared with a description of the movement of the dots; but this is an illusion - both modes of speech have the same meaning. (p. 119)

Thus we are indeed confronted with a volitional bifurcation here: Either we decide to take the positivist stance; then the crucial entailed decision would be the truth theory of meaning with its associated renunciation of independently existing theoretical entities. Or we decide to take the realist/empiricist stance; then the crucial entailed decision would be the probability theory of meaning with its associated endorsement of independently existing theoretical entities. ${ }^{8}$

\section{5 "Illlata", scientific realism and the significance of pragmatism}

No doubt Reichenbach's position in the context of the cubical-world analogy is that of a realist. But what kind of realism is it he defends? Alberto Coffa has suggested to distinguish between a 'heterogeneous' and a 'homogeneous' variant of realism to be found in Experience and Prediction (see Coffa, 1983, p. 271). According to the heterogeneous variant, as it is developed in $\S 14$, realism-understood as full-fledged scientific realism-is closely correlated with causal inductive reasoning. Thus the

\footnotetext{
${ }^{8}$ One of the reviewers of the present paper insinuates that the volitional bifurcation presented sounds indeed like Carnap's position in Scheinprobleme in der Philosophie (1928). Up to this point, that might be so. But see the next section.
} 
cubical-world analogy is designed to clarify that the inference from observable effects to unobservable causes is legitimate. ${ }^{9}$ If, for example, a physicist in the laboratory observes ionization tracks in a cloud chamber she is, according to Reichenbach, warranted to infer to the existence of electrons as the causally responsible entities. The underlying form of realism is heterogeneous because we are dealing here with two different types of entities: those which can be immediately observed and those which can only be inferred. The corresponding scheme of reasoning is causal inductive since an inference is drawn from the correlation of observable effects to a common cause. In his posthumously published book The Direction of Time, Reichenbach hence speaks of the "principle" of the common cause (see Reichenbach, 1956, p. 157; see also Salmon, 1984 in this connection). In chapter IV of Experience and Prediction, on the other hand, he introduces the term illata (derived from the Latin word 'inferre') to denote such inferred entities and comments: "The illata have [...] an existence of their own, as the birds for the people of the cubical world, although they are not accessible to direct observation, that is, to immediate existence." (Reichenbach, 1938, p. 212). ${ }^{10}$

However, regarding this heterogeneous variant of realism, a serious transfer problem reveals itself: Reichenbach employs the probability concept in order to explicate the inferential step from observable concrete entities to what he calls illata. This is a problem insofar as probability, according to Reichenbach, is nothing else but relative frequency (see Reichenbach, 1938, ch. V and esp. Reichenbach, 1935; see further the reconstruction in Galavotti, 2011). As a matter of fact, the corresponding commitment to frequentism in the theory of probability gave repeatedly cause for criticism. We will come back to this point in a moment.

For the time being, tough, some words should be said about how Reichenbach's commitment to frequentism is connected to the cubical-world analogy. In this regard, Elliott Sober (2011, pp. 8-9) has provided instructive interpretative keys. Given Sober's interpretation, observations-in the cubical-world analogy, of given pairs of shadow figures $i$ and $j$-are the sample frequencies. For some range of properties $F$, Reichenbach's claim would be:

(Obs). $\quad \operatorname{frequ}(i$ has $F \& j$ has $F)>\operatorname{frequ}(I$ has $F) \operatorname{frequ}(j$ has $F)$.

\footnotetext{
9 Accordingly, the title of $\S 14$ reads "A cubical world as a model of inferences to unobservable things.".

${ }^{10}$ It is interesting to note that Reichenbach is mentioning Ludwig Boltzmann's defense of the independent existence of atoms in this context. He writes: "Boltzmann's argument in our terminology would read that there are probability inferences to the existence of atoms, that the atoms are a projective complex of concreta, and that it is no objection against the independent reality of the atoms if a 'direct verification' i.e., the determination of a higher weight is physically impossible. Later developments have decided in favor of Boltzmann's opinion; effects have been discovered experimentally which are comparable to a penetration of the walls of the cubical world as described by us. These are the famous discoveries which show individual effects of a single atom, or electron, like the Wilson tracks of alpha and beta particles. It is true that they do not show the individual atom in the same way that we see a tennis ball; but they increase the weight of the hypothesis to such a degree that no practical doubt remains." (1938, pp. 2134). See also Cercignani 1999 and Neuber 2002 in this connection.
} 
Both sides of this inequality imply that $i$ and $j$ are associated with each other. However, according to Reichenbach's cubical-world analogy, there exist two rivaling hypotheses concerning the exact kind of association, namely:

(Common Cause). $i$ 's having $F$ and $j$ 's having $F$ are joint effects of a common cause.

(Coincidence). $\quad i$ 's having $F$ and $j$ 's having $F$ are causally unconnected.

In Reichenbach's view, the realist goes with (Common Cause), while the positivist is committed to (Coincidence). According to Sober, Reichenbach's principal claim, then, would be:

\section{$\operatorname{Pr}($ Obs $\mid$ Common Cause $)>\operatorname{Pr}($ Obs $\mid$ Coincidence $)$.}

Consequently, for Reichenbach, the realist stance itself is more probable than the positivist stance. $^{11}$

So far, so good. But as already indicated, Reichenbach's account did not go uncriticized. For example, Ernest Nagel, in his 1938 review of Reichenbach's Experience and Prediction, writes:

How can a conception of probability, which takes its stand firmly upon interpreting probabilities as relative frequencies in empirical sequences, be made to apply intelligibly to a domain inaccessible to the requisite material investigation? Universes, with or without external worlds, are not so plentiful as blackberries; and not even Reichenbach's ingenuity can make plausible the assumption that a statistical view of probability is relevant to solving such a problem. (Nagel, 1938, p. 271)

\footnotetext{
${ }^{11}$ In order to confront Reichenbach's common cause approach with concrete contemporary scientific practice, Sober (2011, pp. 11-13) provides an enlightening discussion of Einstein's 1936 account of 'gravitational lensing.' Still, it should not go unnoticed that Sober is rather skeptical about the common cause approach as such. Whereas Salmon $(1999$, p. 311) interprets the shadow images in the cubicalworld analogy as having a common cause, Sober thinks the underlying principle "has problems" (p. 11) since its probabilistic formulation requires "prior probabilities for common cause hypotheses" (ibid). However, Salmon's point seems to be that it is just the other way round: on his view "we should invoke Reichenbach's principle of the common cause" (p. 312) because with the help of this principle the problem of "the prior probability of truth of theories that refer to unobservables" (p. 312) can be effectively solved. One can (as Salmon does) refer in this context to Reichenbach's "Remark for the mathematician" (1938, p. 124) where "the rule of Bayes" is explicitly mentioned and commented on (see also p. 390). Yet, as already indicated (and also noted by Salmon), the principle of the common cause itself appears only later, most explicitly in The Direction of Time where Reichenbach states: "If an improbable coincidence has occurred, there must exist a common cause. [...] Chance coincidences, of course, are not impossible [...] The existence of a common cause is therefore [...] not absolutely certain, but only probable. This probability is greatly increased if coincidences occur repeatedly." (Reichenbach 1956, p. 157-8; emphasis in the original). Coming back from the cubical to the real (scientific) world, then, Salmon discusses Jean Perrin' ascertainment of Avogadro's number in order to illustrate the common cause principle which he correctly thinks is implicitly existent already in Reichenbach's 1938 approach. Since both Sober and Salmon provide highly interesting readings of the cubical-world analogy, an extensive comparison of their respective views would be a worthwile topic of its own.
} 
Quite similarly Feigl, in his 1950 "Existential Hypotheses," challenges Reichenbach's attempt at an inductive justification as follows:

The crux of the problem lies in the justification of applying the concept of inductive probability to the inference from the directly verifiable to directly unverifiable assertions. Any straightforward frequency interpretation of probability could serve here only if the success frequencies were ascertainable. This is outright impossible if independent access to the "Illata" is barred. [...] [T] he legitimacy of applying the probability concept to the whole realistic frame, instead of merely to inferences within it, remains painfully questionable. (Feigl, 1950, p. 53)

Thus both Nagel and Feigl are wondering why the probability of repeating observable events should lead to knowledge concerning unobservable entities such as atoms. That frequentism implies inductivism is explicitly claimed by Reichenbach (see 1938, p. 339; further 1951, p. 236). However, he does not provide an answer as to the accessibility of illata or, within the analogy, the birds outside the cube. Frequentism can only tell us what is going on inside the cube, that is, in the realm of observable events. Admittedly, Reichenbach might be right in supposing that - from the perspective of the physicist- "[i]t is highly improbable that the strange coincidences observed for one pair of dots are an effect of pure chance" (1938, p. 120). Moreover, it appears plausible to ask for a "causal connection" (p. 121) here. But on the basis of frequentism alone, this causal connection can hardly be found. Or, as Nagel puts it very aptly in his paper "Probability and Knowledge" from 1939:

[...] Professor Reichenbach is unquestionably a frequentist in his interpretation of "probability" [...]. But what sort of frequencies observable within the cube would be relevant to determine the weight of a theory about things not accessible? Professor Reichenbach does not explain this, and lacking such an explanation we might rest our case as to his not having solved the problem until he does so. (Nagel, 1939, pp. 237-238)

And Nagel (being himself a frequentist) continues:

[T] he extrapolation from observed frequencies within the cube to events inaccessible outside the cube assumes the very point at issue: the existence of an outside the cube could not be in question if the argument is to mean anything. For what else is involved in the supposition that the inhabitants observe shadows on the walls of their world? What would it mean to say that they are hemmed in by "a wall," if the wall did not have an outside as well as an inside? Having assumed so much of a world outside their cube, just what is the problem of the external world to the inhabitants? (p. 238)

To put it slightly differently: The existence of theoretical entities (the birds in the cubical-world analogy) is not at all inferred. Rather, the existence of these entities is theoretically postulated so that-in a second step — it might be asked how probable 
the explanatory hypothesis of their existence actually is. Yet exactly here, Nagel concludes, the frequentist approach is falling short because it is impossible to determine the explanatory hypothesis's Reichenbachian weight by merely determining relative frequencies at the level of observable events. ${ }^{12}$ In short, the heterogeneous variant of realism is severely limited. ${ }^{13}$

So what about the homogeneous variant of realism? Here, it is $\S 17$ of Experience and Prediction that must be consulted. Remarkably, the section is titled "Positivism and Realism as a Problem of Language." Thus Reichenbach is obviously switching from the level of methodology to that of semantics (see also Neuber, 2012a and 2018a, pp. 102-105 in this context). And indeed, at the very beginning of $\S$ 17, Reichenbach makes it clear that (in the course of the preceding section) "[o] ur inquiry about the difference of the positivistic and the realistic conception of the world has taken another turn; this difference has been formulated as the difference of two languages" (p. 145). In point of fact, Reichenbach takes the linguistic turn in its most radical form, namely by maintaining that "an analysis of language is at the same time an analysis of the structure of the world" (ibid.; emphasis added).

It must be recognized that the consequences of this switch are really serious and profound. Had Reichenbach in $\S 14$ argued in terms of effects and their unobservable causes, he now refrains from doing so. Instead, he focuses on the quite different question whether things perceived by us at a certain moment continue to exist if we do not perceive them anymore. According to the homogeneous form of realism, this would surely be the case, that is, a thing perceived as existing at $t_{1}$ and again perceived as existing at $t_{2}$ would be supposed to exist in between $t_{1}$ and $t_{2}$ as well. Following Coffa (1983, p. 271), this form of realism is homogenous insofar as the inference from the perceived (or observed) to the non-perceived (or non-observed) takes place at one and the same ontological level. Accordingly, there is no reflection

\footnotetext{
12 According to Psillos (2011a, p. 32), Reichenbach - not at least because of the infamous base-rate fallacy - is eventually forced to leave the frequentist framework by allowing Bayesian 'prior probabilities' for "inferring from given observations the probabilities of their causes" (Reichenbach 1938, p. 390). However, this makes Reichenbach's whole approach of course inconsistent: as everybody knows, frequentism and Bayesianism exclude each other. Or, as Reichenbach himself declares in his The Rise of Scientific Philosophy: "The rationalist interpretation of probability [i.e., Bayesianism] must be regarded as a remnant of speculative philosophy in a scientific philosophy. [...] The empiricist philosophy of probability is based on the frequency interpretation." (1951, p. 236). Thus, we definitely have another volitional bifurcation here (ignored, though, by Reichenbach in the passage just referred to).

13 It should be noticed that Sober (2011, pp. 13-20) offers a reformulation of Reichenbach's argument in terms of current 'interventionist' accounts of causation (Hacking, Hausman, Woodward, and others). And indeed: the principal obstacle in Reichenbach's analogy seems to be that the cube-inhabitants are not in a position to causally (experimentally or otherwise) manipulate the shadow images (not to speak of the birds themselves). Sober writes: "Reichenbach's cube is a beautiful analogy for the problem of the external world. [...] But there is a disanalogy that needs to be corrected. Because of powerful force fields, the cubists are passive observers of the images on the wall of their cube [...]. In contrast, each of us is related to his or her experiences actively, not passively. We influence which experiences we have by acts of will. This provides us with experimental opportunities that the cubists cannot exploit." (2011, p. 20) To be sure, when discussing atomism (see footnote 9, above), Reichenbach draws on experimental effects being "comparable to a penetration of the walls of the cubical world" (1938, p. 213). However, as far as I can see, this is the only passage where he comes close to the more recent interventionist point of view.
} 
on any relation of causal efficacy between theoretically postulated entities like atoms and the observable phenomena evoked by them. Rather, the decisive question in the context of $\S 17$ is what it means that a thing not perceived right now (like, for example, my bed in the neighbor room) must be supposed to exist all the same.

Moreover, it is highly interesting to observe that it is Carnap who, according to Reichenbach, particularly applied this form of consideration (see Reichenbach, 1938, p. 145 and Carnap, 1928b, Sect. 7). In $§ 29$ of Experience and Prediction, Reichenbach goes as far as to suggest that Carnap was one of the first who realized that a principled distinction between facts and propositions cannot be drawn. Consequently, it would make perfectly good sense to conceive philosophy under the definition of the "analysis of scientific language" (p. 270). "We ourselves," Reichenbach specifies, "have made use of this conception when we reduced the question of the existence of external things to a question of the meaning of sentences" (ibid.).

Now, this sort of lingualization of the whole realism issue combined with the stress on the particularly practical needs of science leads to a significant reformulation of the issue of entailed decisions. For the decisive argument against the positivistic doctrine is now completely subsumed under the regime of practical usefulness. Thus, in $\S 17$ of Experience and Prediction, we find the following declaration:

[T]he decision for the strictly positivistic language would entail the renunciation of any reasonable justification of a great many human actions. The pragmatic idea that the definition of meaning is to be chosen in adaption to the system of human actions, that it is to be determined by the postulate of utilizability, decides, therefore, against the strictly positivistic language. (p. 150)

As a consequence, the realism debate as such apparently loses relevance for Reichenbach. It seems to degenerate to a futile metaphysical dispute, which might have some psychological significance at best. In Reichenbach's words:

Positivists have attacked realism in pretending that it is meaningless to imagine external things which we do not observe, and then have insisted that the only permissible interpretation of propositions about external things is to realize the impressions we should have when the things were observed. This, it seems to me, is the attack of one metaphysician against another; it cannot be the task of scientific philosophy to decide for one side in this struggle. An unprejudiced analysis of scientific propositions shows that the positions of positivism and realism are both rooted in the psychological sphere and that the concept of meaning should be freed from all such psychological components if it is to correspond to the practice of thinking. (pp. 159-60)

All of this comes pretty close to the anti-metaphysical positions of the early Carnap (see esp. Carnap, 1928b; further Carnap, 1934, ch. V) and the later (Viennese) Schlick (see esp. Schlick, 1932). But be that as it may, it can hardly be overlooked that Reichenbach, as regards the constructive part of his argumentation in the given context, definitely enters the field of pragmatism. Already at the end of chapter I of Experience and Prediction, one can read the following: 
[T]here is as much meaning in a proposition as can be utilized for action. With this formulation, the close relation of the probability theory of meaning to pragmatism becomes [...] obvious; we think, though, that our theory, by using the concepts of probability and weight, may furnish a better justification of the relation between meaning and action than pragmatism is able to give. ( $\mathrm{p}$. 80)

Given the problems associated with Reichenbach's plea for a frequentist account of probability, it might be doubted that his particular approach is really superior to pragmatism proper. At any rate, the closeness of Reichenbach's position to essentially pragmatist conceptions and ideas is beyond any doubt. ${ }^{14}$

So we end up with realism being tied to linguistic and psychological issues, to choices. While we started from the viewpoint that what essentially distinguishes logical empiricism from logical positivism is the commitment to a realistic semantics, we are now faced with a pragmatistic attitude that is anything but alien to Carnap and other advocates of a non-realistic variant of logical empiricism.

Finally, some brief remarks concerning the further development of Reichenbach's position. In his 1944 Philosophic Foundations of Quantum Mechanics, he entirely refrains from assuming that realism (be it heterogeneous or homogeneous) is capable of being defended theoretically (viz. inductively). Instead he now assumes that realism is one among several equivalent descriptions, the decision between which can only be made on the basis of a-theoretic conventions (see Reichenbach, 1944, pp. 17-20). Among these equivalent descriptions, the description for which unobservables follow the same laws as observables is called by Reichenbach the "normal system" (p. 19). If there in fact is such a system, is, he maintains, an empirical issue; whether we should really use it, remains in his view a matter of free choice and thus of the applicability of practically adequate conventions. One of these conventions are what he calls "extension rules" (ibid.), which he thinks first of all enable the talk about theoretical entities. In his 1951 The Rise of Scientific Philosophy he puts this point as follows:

There is a plurality of equivalent descriptions, and the usual realistic language in which we describe the physical world is merely one among these descriptions; it is the one which I have called the normal system. Inductive inferences can establish the usual form of statements about an external world only after the rule of identical laws for observables and unobservables has been laid down. This rule has the nature of a definition determining the form of language; it may be called an extension rule of language, because it supplies the means to extend language to a wider domain of objects, including unobserved objects. (Reichenbach, 1951, pp. 266-267)

Carnap's, 1950 "Empiricism, Semantics, and Ontology" comes immediately to mind. But be that as it may; the crucial point is that extension rules now fulfill the

\footnotetext{
14 See in this connection also Reichenbach's 1939 contribution to the Schilpp volume on John Dewey. (For further details, see Godfrey-Smith 2010).
} 
bridging function which inductive inferences had in the 1938 cubical-world analogy. In fact, extension rules first of all help establish the realistic frame within which the inductive inference from observable to unobservable entities can be drawn. More generally speaking, realism has now ultimately been degraded to a dependent variable of an all-encompassing strategy of pragmatization and conventionalization.

\section{Summary and prospect}

In the present paper, it has been shown that Reichenbach's defense of logical empiricism is deeply rooted in realistic thinking. The cubical-world analogy served as the paradigm case in point in this regard. However, as has been outlined toward the end of the paper, Reichenbach's argumentation in Experience and Prediction oscillates between two readings: a full-fledged scientific realist reading and an eminently pragmatist reading. In the publications following Experience and Prediction, Reichenbach significantly reinforces the pragmatist element in his thinking. On the whole, his later approach tends to dissolve the realism issue to a matter of mere language choice.

Regarding the impact of Reichenbach's, 1938 attempt at reconciling logical empiricism and scientific realism, it is interesting to note that it was the Finnish thinker Eino Kaila who, in his 1941 contribution "Über den physikalischen Realitätsbegriff," sought to restrict the conventional-pragmatic element in Reichenbach's account by an ontologically affirmative interpretation of the physical concept of invariance (for further details, see Neuber, 2012b and Neuber, 2018a, ch. 9). Nine years later, Herbert Feigl, in his "Existential Hypotheses" on the one hand criticized, as we have seen, the Reichenbachian commitment to a quasi-inductive justification of the realistic frame; yet, on the other hand, Feigl too ended up with a fatally pragmatized/conventionalized form of 'scientific realism' (for further details, see Neuber, 2011 and Neuber, 2018a, ch. 5). Last but not least, Reichenbach's student Hilary Putnam is worth mentioning in our context. The latter's switch from a naturalistic to a pragmatized ('internal') variant of realism (see Putnam, 1975 and Putnam, 1981) comes astonishingly close to Reichenbach's switch from heterogeneous realism in $\S$ 14 to homogeneous realism in $\S 17$ of Experience and Prediction. ${ }^{15}$ On the whole, Reichenbach's, 1938 contribution set the stage for discussions still going on today, although the logical empiricist program is commonly judged as being dead. Ironically, it is the scientific realists who (together with Thomas Kuhn) are seen as the assassinators. Yet, historical examinations like the present one might help seeing things in a more differentiated manner. As a matter of fact, current scientific realism evolved out of logical empirical endeavors such as Reichenbach's (for a brief overview, see Neuber, 2018b).

\footnotetext{
15 As I have shown elsewhere (see Neuber 2014 and 2018a, pp. 157-160), something similar can be determined by comparing relevant passages in Psillos 1999 and Psillos 2011b.
} 
Acknowledgements I wish to thank Joern Ahrendt for his invaluable practical support when I had a broken leg and wrote the present paper. Furthermore I wish to thank two anonymous reviewers of this journal for very helpful critical comments and suggestions for improvement.

Funding Open Access funding enabled and organized by Projekt DEAL.

Open Access This article is licensed under a Creative Commons Attribution 4.0 International License, which permits use, sharing, adaptation, distribution and reproduction in any medium or format, as long as you give appropriate credit to the original author(s) and the source, provide a link to the Creative Commons licence, and indicate if changes were made. The images or other third party material in this article are included in the article's Creative Commons licence, unless indicated otherwise in a credit line to the material. If material is not included in the article's Creative Commons licence and your intended use is not permitted by statutory regulation or exceeds the permitted use, you will need to obtain permission directly from the copyright holder. To view a copy of this licence, visit http://creativecommons.org/licen ses/by/4.0/.

\section{References}

Brown, J. R. (2004). Why thought experiments transcend empiricism. In C. Hitchcock (Ed.), Contemporary debates in the philosophy of science. (pp. 23-43). Blackwell.

Carnap, R. (1928a). Der logische Aufbau der Welt. Weltkreis-Verlag.

Carnap, R. (1928b). Scheinprobleme in der philosophie. Weltkreis-Verlag.

Carnap, R. (1934). Logische syntax der sprache. Springer.

Carnap, R. (1935). Wahrheit und Bewährung. Actes Du Congrès International De Philosophie Scientifique, IV Induction Et Probabilité, Actualités Scientifiques Et Industrielles, 391, 18-23

Carnap, Rudolf. 1936/37. Testability and meaning. Philosophy of Science, 3 \& 4, 419-471 and 1-40.

Carnap, R. (1950). Empiricism, semantics, and ontology. Revue Internationale De Philosophie, 4, 20-40

Cercignani, C. (1999). Ludwig Boltzmann: The man who trusted atoms. Oxford University Press.

Coffa, A. (1983). Erläuterungen, Bemerke und Verweise zum Buch, Erfahrung und Prognose. In A. Kamlah \& M. Reichenbach (Eds.), Hans reichenbach gesammelte werke. (Vol. 4, pp. 255-297). Braunschweig: Vieweg.

Coffa, A. (1991). The semantic tradition from Kant to Carnap: To the Vienna station. Cambridge University Press.

Eberhardt, F. (2011). Reliability via synthetic apriori: Reichenbach's doctoral thesis on probability. Synthese, 181, 125-136

Feigl, H. (1950). Existential hypotheses: Realistic versus phenomenalistic interpretations. Philosophy of Science, 17, 192-223

Feigl, H. (1951). Confirmability and confirmation. Revue Internationale De Philosophie, 5, 268-279

Feigl, H. 1981. Inquiries and provocations. Selected writings, 1927-1974, edited by R. S. Cohen. Dordrecht: Reidel.

Feigl, H., \& Blumberg, A. E. (1931). Logical positivism: A new movement in European philosophy. The Journal of Philosophy, 17, 281-296

Friedman, M. (1999). Reconsidering logical positivism. Cambridge University Press.

Galavotti, M. C. (2011). On Hans Reichenbach's inductivism. Synthese, 181, 95-111

Godfry-Smith, P. (2010). Dewey and the subject-matter of science. In J. Shook \& P. Kurtz (Eds.), Dewey's enduring impact: Essays on America's philosopher. (pp. 73-86). Prometheus Books.

Hempel, C. G. (1950). Problems and changes in the empiricist criterion of meaning. Revue Internationale De Philosophie, 4, 41-63

Irzik, G., \& Sober, E. 2011. Introduction to the synthese special issue on Hans Reichenbach, Istanbul, experience and prediction. Synthese, 181, 1-2.

K., E. (1930). Der logistische Neupositivismus Eine kritische Studie. Turku: Finn. Universität.

Kaila, E. Über den physikalischen Realitätsbegriff. Zweiter Beitrag zum logischen Empirismus. Helsinki: Edidit Societas Philosophica.

Milkov, N., \& Peckhaus, V. (Eds.). (2013). The Berlin Group and the philosophy of logical empiricism. Springer. 
Nagel, E. (1936). Impressions and appraisals of analytic philosophy in Europe II. The Journal of Philosophy, 33, 29-53

Nagel, E. (1938). Review of H. Reichenbach, Experience and prediction. The Journal of Philosophy, 35, $270-272$

Nagel, E. (1939). Probability and the theory of knowledge. Philosophy of Science, 6, 212-253

Neuber, M. (2002). Physics without pictures? The Ostwald-Boltzmann controversy and Mach's (unnoticed) middle-way. In M. Heidelberger \& F. Stadler (Eds.), History of philosophy of science: New trends and perspectives. (pp. 185-198). Kluwer.

Neuber, M. (2011). Feigl's 'Scientific Realism.' Philosophy of Science, 78, 165-183

Neuber, M. (2012a). Realism as a problem of language. From Carnap to Reichenbach and Kaila. In R. Creath (Ed.), Rudolf Carnap and the legacy of logical empiricism. (pp. 37-56). Dordrecht: Springer.

Neuber, M. (2012b). Invariance, structure, Measurement-Eino Kaila and the history of logical empiricism. Theoria, 78, 358-383

Neuber, M. (2014). Is logical empiricism compatible with scientific realism? In M. C. Galavotti, E. Nemeth, \& F. Stadler (Eds.), European philosophy of science-Philosophy of science in Europe and the Viennese Heritage. (pp. 249-262). Springer.

Neuber, Matthias. 2018a. Der Realismus im logischen Empirismus. Eine Studie zur Geschichte der Wissenschaftsphilosophie. Cham: Springer.

Neuber, M. (2018). Realism and logical empiricism. In J. Saatsi (Ed.), The Routledge handbook of scientific realism. (pp. 7-19). Routledge.

Norton, J. D. (2004). Why thought experiments do not transcend empiricism. In C. Hitchcock (Ed.), Contemporary debates in the philosophy of science. (pp. 44-66). Blackwell.

Psillos, S. (1999). Scientific realism: How science tracks truth. Routledge.

Psillos, S. (2011). Reichenbach's Argument for Scientific Realism. Synthese, 181, 23-40

Psillos, S. (2011). Choosing the realist framework. Synthese, 180, 301-316

Putnam, H. (1975). Explanation and Reference. Proceedings and Addresses of the American Philosophical Association, 50, 483-498

Putnam, H. (1981). Reason, truth and history. Cambridge University Press.

Reichenbach, H. (1915). Der Begriff der Wahrscheinlichkeit für die mathematische Darstellung der Wirklichkeit. Barth.

Reichenbach, H. (1920). Relativitätstheorie und Erkenntnis A Priori. Springer.

Reichenbach, H. (1921). Bericht über eine Axiomatik der Einsteinschen Raum-Zeit-Lehre. Physikalische Zeitschrift, 22, 683-688

Reichenbach, H. (1930). Kausalität und Wahrscheinlichkeit. Erkenntnis, 1, 158-188

Reichenbach, H. (1933). Review of R. Carnap, Der logische Aufbau der Welt. Kant-Studien, 38, 199-201

Reichenbach, H. (1935). Wahrscheinlichkeitslehre. Leyden: Sijthoff.

Reichenbach, H. (1936). Logistic empiricism in Germany and the present state of its problems. The Journal of Philosophy, 33, 141-155

Reichenbach, H. (1938). Experience and prediction: An analysis of the foundations and the structure of knowledge. University of Chicago Press.

Reichenbach, H. (1939). Dewey's theory of science. In P. Schilpp \& L. Hahn (Eds.), The philosophy of John Dewey. (pp. 159-192). Open Court.

Reichenbach, H. (1944). Philosophic foundations of quantum mechanics. University of California Press.

Reichenbach, H. (1951). The rise of scientific philosophy. University of California Press.

Reichenbach, H. (1956). The direction of time. University of California Press.

Salmon, W. (1984). Scientific explanation and the causal structure of the world. Princeton University Press.

Salmon, W. (1994). Carnap, Hempel, and Reichenbach on scientific realism. In W. Salmon \& G. Wolters (Eds.), Logic, language, and the structure of scientific theories. (pp. 237-254). University of Pittsburgh Press.

Salmon, W. (1999). Ornithology in a cubical world: Reichenbach on scientific realism. In D. Greenberger, W. L. Reiter, \& A. Zeilinger (Eds.), Epistemological and experimental perspectives on quantum physics. (pp. 303-316). Kluwer.

Schlick, M. (1932). Positivismus und Realismus. Erkenntnis, 3, 1-31

Sober, E. (2011). Reichenbach's cubical universe and the problem of the external world. Synthese, 181, $3-21$

Uebel, T. (2007). Empiricism at the crossroads: The Vienna circle's protocol-sentence debate. Open Court. 
Uebel, T. (2013). 'Logical positivism'- 'Logical empiricism': What's in a name? Perspectives on Science, $21,58-99$

Publisher's Note Springer Nature remains neutral with regard to jurisdictional claims in published maps and institutional affiliations. 